\title{
KEY PERFORMANCE INDICATORS FOR THE NATO CENTRES OF EXCELLENCE
}

\author{
Alexandru KIS*, Evangelos THEODORIDIS** \\ *NATO HUMINT Centre of Excellence, Oradea, Romania, **Greece \\ alexandru.kis@natohcoe.org
}

\begin{abstract}
The NATO Centres of Excellence (COEs), entities involved in various fields of transformation in support of the Alliance, are subject of different levels of accreditation performed by NATO. An important aspect of such recognition comes with the NATO institutional accreditation for Quality Assurance (QA) in the case of the COEs involved in education and training delivery (alongside other NATO, National and Partner Education and Training Centres). The NATO QA seal is the trustworthy mark that a COE fulfils the expected quality requirements (based on a solid Quality Management System) in the educational process, and provides deliverables "fit for purpose” as solutions for the NATO education and training requirements. While the individual strategies of the COEs are pretty much different in this endeavour, we would outline the commonality of the standards they rely on. This paper focuses on institutional performance measurement as reference in the Quality Management System, trying to identify benchmarks for Key Performance Indicators (KPIs) based on the current experience at the COEs level - extended to the wider NATO Transformation Network and shared best practice. DISCLAIMER: This paper expresses the views, interpretations, and independent position of the authors. It should not be regarded as an official document, nor expressing formal opinions or policies, of NATO or the HUMINT Centre of Excellence (HCOE).
\end{abstract}

Keywords: NATO, Centre of Excellence, Quality Assurance, Key Performance Indicators

\section{Introduction. Key Performance \\ Indicators in the Measurement of the Institutional Performance}

Performance is a permanent concern for any enterprise. This is actually the point behind any investment, in any area of interest, and is strictly related to the goal of that venture. In this respect, there are many management tools that support the activity within an organization, dedicated to control its effectiveness and adjust the use of resources and efficiency of the processes, aligned to the desired end state.

One of the most used diagnose model is related to the clustered assessment of a series of parameters, vital for the activity Key Performance Indicators (KPIs). KPIs are relatively complex instruments for performance measurement, evaluating the success of the organization in terms of quality and quantity, checked against a plan (fulfillment of stages), or a strategic vision for institutional development (progress record).

The major challenge on establishing/ selecting understandable, meaningful, and measurable KPIs stays with a deep understanding of what is important for an institution (indicators of functional areas/ products), what is relevant for influencing 
the evolution of the monitored process (assessment techniques in support to the decision making), and how to depict these aspects (dashboard view).

Identifying performance indicators of the organization are dependent on the nature of the activity, following a staged approach. Based on the functional process, requirements (goals) are set and periodically measured against the results, enabling variances and adaptation of processes or resources to achieve short-term goals; in this respect, institutional resilience is of major importance. This control activity covers all the lucrative layers of the organization, from leadership down to employees.

KPI examples in financial or economic environment are facile to design, just thinking about the functional algorithm of any enterprise, where input-processingoutput scheme is judged in terms of resource-wise efficiency and financial effectiveness; in this case, indicators like: procurement and suppliers, manufacturing cost, rebut rates, sales, stocks, warehousing, transportation, marketing effects, profitability, or customers' satisfaction, number, profile, geographical coverage, and even firm's social responsibility projects, are to be considered.

On the other hand, more abstract and complex activity is harder to be accurately measured, as long as some indicators may be scarcely possible to quantify, and subsequent KPIs would provide rough guidance, rather than a precise benchmark [1]. Some standard KPIs for services providers may offer inspiration for our effort. Infrastructure capacity utilization (utilization rates for resident services) offers an insight into the usefulness, affordability, efficiency and/or effectiveness of those services; availability rates define the interface with the customers (pull/push aspects in the communication outreach); Service Level Agreements and Service Level Target Attainment is a balance between the plan and the achievements (applicable to a specific Program of Work/ production level of completion); Days of Project Backlog is a measure of project team availability, thus sufficiency of human resources to complete incumbent tasks; Percent of Projects Delivered on Time is an indicator of projects' timeliness, requiring an analysis on the causes for delays - scope creep or inadequate resources, or poorly designed project, etc. [2]

However, regardless the domains of applicability, the SMART (Specific, Measurable, Achievable, Relevant and Timely) criteria are commonly used as principles to be followed in establishing KPIs. Accordingly, a KPI:

- has a Specific purpose for the business,

- is Measurable (against the target value) to really get a value of the KPI,

- the defined norms have to be Achievable, and preferably their fulfillment shouldn't be usually hampered by factors out of the control of the organization,

- the improvement of a KPI has to be Relevant to the success of the organization, and

- it must be Time phased, which means the value or outcomes are shown for a predefined and relevant period. [3]

Further on, KPIs have to be thoroughly monitored and addressed by the institution management.

Dashboards provide a comprehensive and quick view of KPIs; their automated link with a database (digital dashboards, either stand alone software applications, webbrowser based applications, and widget applications) ensures permanent update, time effective identification of trends, harmonized efforts, adapted algorithms, and finally supports decision making processes. $\mathrm{S}$. Few categorizes dashboards according to their roles, broken down at strategic, analytical, operational, or informational levels [4], providing customized information to all corporate levels. A dashboard view model is available in the figure 1 , incorporating different widgets 
that offer adapted visual meters of KPIs for various functions within an enterprise.

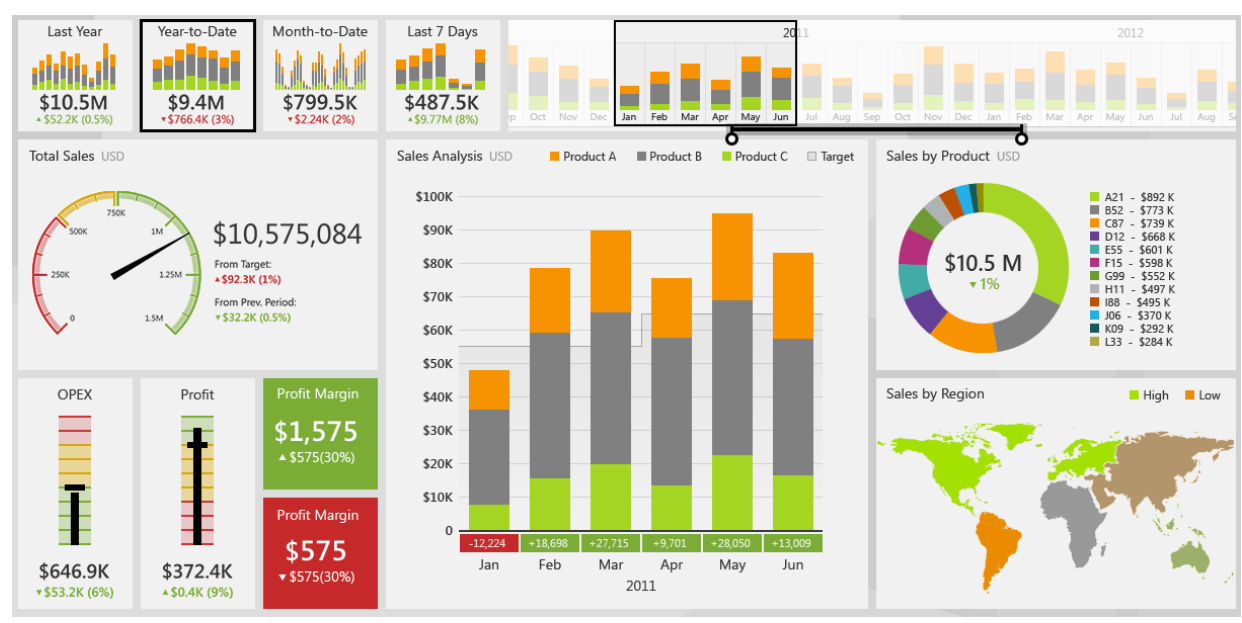

Figure 1: KPIs dashboard view [5]

In order to be effective, dashboards have to be simple, encompassing only meaningful data of critical indicators, with minimum distractions. Design solutions for dashboards can be found in ConceptDraw PRO software, where the displayed objects are live and vector objects, linked to the data source (MS Excel spreadsheet or text file) and available for reviewing, modifying, or converting to a variety of formats (PDF file, MS PowerPoint, MS Visio, and many other graphic formats) from the ConceptDraw STORE. [6]

Having an overall picture on how KPIs stand into a generic organizational model, the next chapter will outline the institutional characteristics of the NATO Centres of Excellence (COEs), in order to ensure an accurate understanding of the functions to which we look to apply KPIs.

\section{NATO Centres of Excellence's Contribution to NATO}

The 2002 Prague Summit represented a starting point for a revolutionary change in the concept and military structure of the North-Atlantic Alliance. The process, aiming for a leaner and more efficient organization, paved the way for the establishment of NATO COEs international military organizations outside the NATO Command Structure (NCS), but part of a wider framework supporting NATO Command Arrangements - in order to complement Alliance's resources and support its transformation process and capabilities development. Based on its academic, analytical, conceptual and/or operational performance, the network, consisting nowadays of 24 accredited Centres [7] provides a flexible pool of recognized expertise in various domains of interest, manifested into work fields commonly known as transformation pillars: Concept Development and Experimentation; Doctrine Development and Standardization; Education and Training; Lessons Learned/ Best Practices and Analysis.

The Concept of a COE offers a primary insight into the scope and guiding principles of establishing these institutions. Primarily, a NATO COE has to comply with the rules set in the Military Committee (MC) Concept for Centres of Excellence [8] - offering support to NATO in condition of no duplication of assets and resources, or competing with existing NATO activities and capabilities - and to conform to NATO policy, doctrines, directives, procedures, and standards. Secondly, the NATO COEs are assessed by Headquarters Supreme 
Allied Command Transformation (HQ SACT) based on the MC approved Criteria [9] for accreditation as NATO Centres of Excellence, and periodically re-assessed in order to ensure that the products and services provided by NATO COEs remain consistent with the quality, standards, practices and procedures within NATO. Thus, we can outline a first set of basic requirements that can be recognized as institutional marks for NATO COEs' performance (and described in the constituting Memoranda of Understanding and internal directives and SOPs), in direct correlation with the functionality expressed in the COEs' Programs of Work (POW).
NATO COEs' contribution to the Alliance is quantified in many terms, which are interdependent to some extent. First of all, the COEs' POW mainstream activities have to answer the NATO Requests for Support (RFS), which usually emerge as top-down directions or bottom-up initiatives. Some of these activities are incumbent with a series of assumed functions in NATO, such as Department Head, doctrine/ standards custodian, or manager for Lessons Learned/ Best Practices (LL/BP) Communities of Interest (figure 2), or derive from COEs participation in various working groups or in NATO concepts development.

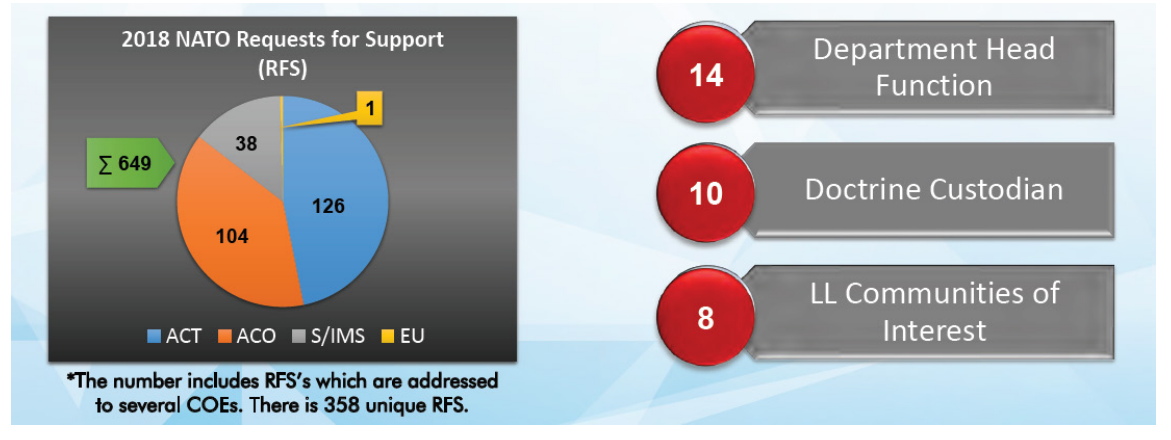

Figure 2: NATO COEs' contribution to the Alliance [10]

In this respect, we would like to outline the outstanding position of the NATO HUMINT COE hosted by Romania in Oradea, which supports all initiatives and assumes the largest possible array of responsibilities in the benefit of the Alliance: NATO HUMINT working groups leadership, HUMINT doctrine and standards custodian, headship of LL/BP and Education \& Training Communities of Interest in NATO, project manager for a series of initiatives in support of the NATO capabilities development, Department Head for HUMINT E\&T in NATO, NATO accredited education and training provider, Officer Conducting the Exercise (OCE) and host of the NATO HUMINT exercise [11]. As mentioned above, an important aspect of the COEs' contribution to NATO is offering education and training solutions, thus acting as an E\&T provider alongside an extended range of other contributors involved in this endeavour: NATO Education and Training Facilities (ETFs), Partner Training and Education Centers (PTECs), Partnership for Peace (PfP) Consortium of Defense Academies and Security Studies Institutes, National and Multinational Training Centers, etc. However, the NATO certification of the courses is dependent on their adaptation to the NATO requirements and institutional accreditation. The accreditation letter is awarded to any relevant institution with reference to: internal quality assurance systems and procedures for the maintenance of quality standards; procedures effectively applied at each Depth of Knowledge level to ensure the quality of individual curriculum; effective and regular processes 
of reviewing the quality of programmes and the standards of curriculum, and implementing the required changes, developments and enhancements; accurate, complete and reliable information about the quality of the institutions programmes and the standards of its curriculum. [12]

For the NATO COEs, this is a second level of formal endorsement that examines the organizations' adherence to commonly recognized educational standards based upon existing NATO policy and procedures, and further validate their contribution to NATO. To date, 23 E\&T institutions are unconditionally accredited by NATO, one achieved conditional accreditation, and other 12 are in the accreditation process. Regarding the courses registered into the online Education and Training Opportunities Catalogue (ETOC) [13], their number reflects an unbalanced ratio between the NATO certified courses (270 approved - thus answering NATO requirements and being provided by NATO accredited institutions; 88 selected - answering NATO requirements, but offered by non-NATO accredited institutions) and those listed (497 courses registered as E\&IT development opportunities in support of the NATO/Partner Nations or other interested entities).

\section{The Quality Assurance Stance in the NATO Centres of Excellence. From Quality Assurance to Key Performance Indicators}

The institutional accreditation is conditioned by the implementation of an effective internal Quality Management System (QMS) and provision of evidence for their contribution to NATO. The NATO Quality Assurance (QA) principles and standards for Education and Training are inspired from European rules for Higher Education, adapted to NATO needs, and are designed to ensure the highest possible degree of quality for all learners, while providing autonomy and flexibility to the education and individual training providers [14].

The internal QMS covers not only educational aspects, but everything related to the functionality of the COE from the perspective of its mission and expected deliverables (the contribution to NATO) in relation to its educational services. It supports the overall management of the institution, increasing its autonomy, contributing to resilience and sustainability, the optimal use of resources, improving communication and relationship with stakeholders and customers, and finally enhancing the COEs' services, based on the principle and the adopted mechanisms of permanent improvement.

The concept of NATO Quality Assurance/ NATO QMS is founded on the NATO Education, Training, Exercises and Evaluation (ETEE) Policy and is described in detail in the Bi-Strategic Command Education and Individual Training Directive 075-007. The prospect is that a COE would have all relevant topics covered by a QA Policy; such policies are publicly available on the websites of some COEs or PTECs, and have offered a primary exploration layer for this paper.

Basically, the QA Policy has to answer the way the institution reflects NATO QA standards (existence and implementation of QA policy and procedures; staff/instructor development processes; information systems and knowledge management; public information; definition and delivery of instruction in line with NATO Systems Approach to Training model; student assessment criteria, regulations, and procedures; appropriate learning resources and student support), proves sustainable leadership and management, is prone to provide education and training services and answers the Alliance requirements, supports the discipline management, and generally supplies NATO capabilities development in different functional areas. 
Further on, COEs' educational services are assessed in matters of performance (quality) and production (quantity). The KPIs analysis is part of the Quality Management and contributes to the proactive nature and orientation toward future of the whole quality system.

In the following paragraphs, we will briefly summarize the current practice in the education and training environment, and especially in the COEs' setting, with regard to institutional KPIs.

KPIs analyzed in the Brasov-based NATO Partner Education and Training Center (PTEC) Regional Department of Defense Resources Management Studies/ DRESMARA QA Board include both quantity and quality aspects: [15]

a. quantity metrics:

- number of resident courses/ iterations;

- number of ADL iterations;

- number of students trained in resident courses and ADL;

- number of students/ alumni using the DRESMARA portal;

- \% of courses with up to date Course Control Documents (CCDs);

- \% of Post Course Reviews (PCRs) produced/ iterations conducted;

- \% of Course Directors/ instructors monitored for the year;

- $\%$ of courses audited for the year;

- \% of Course Review Boards (CRBs) conducted for the year.

b. quality markers/ student satisfaction based on:

- difficulty level of the material;

- value of the course in their current and future job;

- appropriateness of time allocated to the course, and

- intention to recommend the course to others.

At a glance, we can observe the selected indicators as being relevant for determining the evolution in time for "numbers" as marks for efficiency in production and commitment to improvement. On the quality side, the student satisfaction is a commonly recognized measurement supporting the adjustment of the product (course) in terms of difficulty (courseware complexity vs. target audience), relevance for customers (teaching points in line with task/ expected performance objectives), resources allocation to achieve the end state (time) and subjective feeling toward utility of the course.

In the COEs' arena, the Military Police (MP) COE emphasizes in its QA Policy the functional areas to which it applies KPIs: $\mathrm{DH}$, doctrine and standardization, E\&T, LL, security support and administration, and QA, further processing detailed indicators for each reference. KPIs and achievement indicators are internally published in order to record the progress toward realizing the defined strategic plans and objectives.

The KPIs measurement tool provides a dashboard overview for related core business statistics, feeding the analysis in support of the institutional management. The outcome is further considered in decision making process, pertaining to the responsiveness for NATO E\&T requirements, assessment of the courses' standards, collection of LL/BP for selfassessment and permanent improvement, participation in staff development, and involvement in the NATO LL/BP process. [16]

For the Counter Improvised Explosive Devices (CIED) COE, KPIs are focused on critical aspects of institutional performance, like: [17]

- number of institutional hosted events;

- number of students trained;

- graduation rate;

- student application rate;

- percentage of students graduating the courses;

- quality of the courses reflected by students (critic sheets).

- percentage of students living in the COE Lodge/Hotel; 
- percentage of activities achieved (reported to POW).

Part of the assessed parameters is relevant at institutional level, quantifying the level of involvement in the most important activities, the ratio of POW's accomplished activities, and the attractiveness of the accommodation services provided. On the other hand, education and training activities are important from both quantity and customer satisfaction.

The Civil-Military Cooperation COE (CCOE) expresses its commitment to an enhanced E\&T quality by ensuring a match between required skills and knowledge acquisition with the appropriate educational solution (basically fulfilling the NATO Global Programming command) and systematically evaluating aspects of provision of E\&T by:

- analyzing translation of operational requirements into education and training objectives within a subject, programme, module and/or course,

- assessing the established standards to which the courses adhere,

- collaborating with ACT and the Requirement Authority (RA) to ensure courses and curricula are conform to NATO requirements and consistent with NATO PE/CE Job Descriptions,

- $\quad$ sharing best practice,

- participating in staff development,

- monitoring and reviewing as part of self-assessment and development planning,

- participating in NATO's Lessons Identified and Lessons Learned Process,

- implementing most recent learning methodologies;

- fully integrating e-Learning/ Advanced Distributed Learning (ADL). [18]

The listed indicators represent a selection of Quality Assurance standards and Global Programming requirements, which depicts a strategic matrix for the CCOE, applicable at institutional level.
The Military Medicine (MELMID) COE ensures compliancy with ISO 9001/2008 (currently revised by ISO 9001/2015) for its Quality Management System, being oriented to demonstrate its ability to consistently provide product that meets customer and applicable statutory and regulatory requirements, and aiming to enhance customer satisfaction through the effective application of the system, including processes for continual improvement of the system and the assurance of conformity to customer and applicable statutory and regulatory requirements. [19] All ISO 9001 requirements are generic and are intended to be applicable to all organizations, regardless of type, size and product provided.

Particularly, the MELMID COE QA Management Review is based on considerations retrieved from results of institutional Strengths, Weaknesses, Opportunities, and Threats (SWOT) analysis, feedback from E\&T activity, influences and changes of circumstances that may affect the QA management system (e.g. human resources: HOTO of QA responsibilities, personnel rotation based on national regulations; support resources requirements, etc.). [20] In this respect, performance measurement focuses on a series of quality and quantity indicators: [21]

- number of students trained in COE courses or number of attendees at a conference;

- number of MILMED COE courses, conferences and workshops;

- variance between expected audience quality and quality of enrolled students/attendees;

- number of nations in attendance at MILMED COE events;

- number of other institutions (COEs, PTECs, Industry, etc.) represented at MILMED COE events;

- number of ADL courses; 
- number of students trained with ADL courses;

- number of students/ authorized users utilizing the training portal;

- number of Mobile Training Teams (MTTs);

- number of students served by the MTT;

- participant satisfaction based on:

olearning objectives;

odifficulty of the level of the material;

ovalue of event in their current/ future job;

o appropriateness of the time allocated to the event;

owould recommend this event to others.

- \% of course with updated Course Control Documents (CCDs);

- \% of Post-Course Reviews (PCRs) produced/iterations conducted;

- \% of course directors/ instructors monitored for the year;

- $\%$ of courses audited for the year;

- \% of Course Review Boards conducted for the year;

- number of custodian doctrines meeting the timeline requirements.

The figures are relevant for the institution's proficiency in delivering services to its customers, although some of the analyzed aspects are not necessarily related to performance, but useful in controlling and orienting the processes. Moreover, a critical review would reveal that the evolution of the number of courses may be out of the institution's control, and more dependent on Training Requirements Analysis. However, there is a strong commitment to customer satisfaction - the hot spot for KPIs - in the educational and individual training environment.

The last analyzed institution - NATO Stability Policing (SP) COE - defines its triennial strategic objectives and intermediate goals as main reference for the annual POW, making them the target against which the institutional performance is measured. Thus, development of the network of partners, creation of relevant SP documents for the specialty library, proving effectiveness in achieving the POW targets (balanced by resources' availability), endurance of the NATO SP education and training requirements, SP $\mathrm{COE}$ organizational adaptation to the identified needs (institutional resilience), or achievement of relevant functional positions in NATO (e.g. QA accreditation) [22] are items on the scale of institutional success.

From the examples analyzed in this chapter, we can conclude a series of practices adopted in establishing KPIs in the NATO COEs:

- KPIs have different relevance if we refer to the leadership's vision and institutional strategic development or a current management control function focused on the evolution of internal systemic processes (the functional areas - doctrine development, education and training, LL/BP management, or concept development and experimentation). In the first case, the accomplishment of intermediary steps toward the strategic goals are assessed for a longer (established) period of time, while the functional areas are more dependent to the yearly POW cycle and are characterized by repetitive iterations of different events/ project stages, with some variations.

- Quantitative KPIs are convincingly relevant to assess production (number of courses/ events, course demand level, number of students/attendants, number of publications issued, ADL accessibility and attractiveness expressed in the number of students who performed on-line courses, mobile E\&T effectiveness in the larger educational picture, etc.).

- As shown, numbers are also relevant for expressing the commitment to quality assurance and quality control: 
number of quality audits (reviews) for courses/ series of courses; number of evaluations for instructors/ invited speakers and others; however, COEs are supposed to have specific QA provisions that regulate the frequency of such control activities, thus the overall relevance of such metrics is less important.

- Numbers matter in expressing the COEs' outreach, quantifying the overall contribution to NATO's initiatives, connection/ collaboration with other entities and the Academic relevance.

- Concern for personal/professional development of the faculty and staff - as a QA pillar - can be also expressed in numbers and linked to a plan. Quantifying individual competences may give a pertinent picture of the knowledge and skills resources available to develop a project.

Quality KPIs are essentially focused on the customers' satisfaction for the services provided, "sliced" into details that further support the commitment to permanent improvement. To make a better course, you need to know: how well the learning objectives have been achieved, how the courseware supports the education, in which measure the course is useful for the students, if timing is properly allocated for classes, if theory is well connected to practice, and so on. Furthermore, customer satisfaction is extended to additional services (accommodation, logistics, infrastructure, medical support, etc.) that define the big picture of relevance for a solid and comprehensive Quality Management System.

\section{A Key Performance Indicators Baseline for NATO Centres of Excellence} Starting from the considerations set in the previous chapters, a first principle in elaborating KPIs for NATO COEs is considering the functional level addressed.

The primary mission of COEs is given by their Concept and further detailed in the Memoranda of Understanding signed by Participating Nations/ entities and ACT. Derived from this, the COEs' leaderships express their vision for the institutional and production development and a strategy to achieve the goals, which is the strategic level of measurable performance indicators. The strategic KPIs usually subsume a series of operational KPIs, as long as development programs have strong operationalized components at the functional level. In this respect, a generic working model applicable for this purpose is the top-down approach to measure/ control the strategic success proposed by D. Walker: starting from the desired endstate, operational tasks/ objectives of the functional areas are regularly evaluated based on designed KPIs (figure 3) and established metrics (here comes the value of the dashboard view for all relevant parameters); at the end, this algorithm will drive to remedial courses of action, just like the Lessons Learned process. [23]

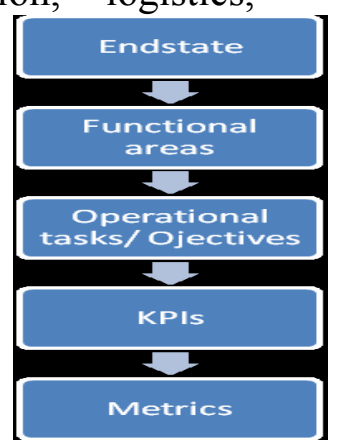

Figure 3: An algorithm for success assessment at institutional level 
One important point in the COEs' performance evaluation at strategic level (at least for those enrolled in education and training) is that academic activity should be compliant with the QA Policy. In this respect, consideration of QA standards and NATO standards in establishing performance indicators becomes a must. Aspects that are directly influenced at micromanagement level (chiefs of sections/ offices, officers of primary responsibility, course directors, etc.) like public communication, internal and external feedback collection and analysis, staff development, etc., are common denominators for measuring the performance of an academic entity from a QA standpoint at strategic level.

Other strategic KPIs for COEs (derived from the strategic vision) can focus on the COE's relevance within its Community of Interest.

On one hand, the importance is given by the COE's level of involvement in all transformation pillars and the achieved success, measured against the desired endstate, e.g.: leadership of the NATO Working Group for a particular domain, custodianship of the NATO doctrine and other standards for the covered discipline, NATO QA certification for the E\&T providers, management of the NATO specialty LL/BP database, etc. If these elements address quality aspects, a COE's relevance in NATO can be also expressed by a quantitative comparison vs. the contribution of other COEs, and depicted into a comparative chart [24].

On the other hand, the involvement in the Community of Interest means supporting the overall capability development. The evolution of a capability follows a programme (usually set in the specialty working group and sequentially addressed and measured by completion of action items covering specific aspects encompassed in the DOTMLPFI (Doctrine, Organization, Training, Materiel,
Leadership, Personnel, Facilities, Interoperability) spectrum.

Another reference for strategic-level KPIs is provided by the Institutional Review process, which ensures the assessment of some critical questions related to the management of the COE's role as E\&T provider in support of NATO (which leads to a courses-centric analysis) and the applied QMS standards. [25] Furthermore, ACT encourages Education and Training Facilities (ETFs) that have completed institutional accreditation to participate in, and summarize their academic partnership activities and achievements within their annual QA Report; consequently, Academic Outreach metrics can be also quantified as strategic level KPIs.

Last, but not least, the COE's Program of Work (POW) is worth a special attention, as a control tool for the activities planned and executed along the covered period of time (usually, one year). Quantitatively, it can be easily assessed in terms of completion ratio; however, the institutional success related to the POW is given by the quality aspects, which can be counted in the fulfillment of the established objectives by functional areas.

\subsection{Key Performance Indicators in Education and Training}

As this is the main reference in QA, the NATO Bi-SC Directive 075-007 provides extensive guidance for E\&T areas of evaluation, describing the methodology for the Post-Course Review (PCR) (aiming to extensively assess the quality of a course as educational solution for NATO requirements, and support its improvement), or course monitoring (focused on course quality from the perspective of instructional effectiveness performance of individual instructors), and including a large array of supporting metrics. [26] A single point to emphasize: the process has to cover both internal evaluation, based on data collected from a large array of sources within the educational facility, and external 
evaluation, in order to assess the utility of the competences achieved in the course either on the job, or within the operational context.

With this external feedback, comes into the scene the need to evaluate aspects emerging from the Global Programming approach, and first of all the fulfillment of the E\&T requirements to which the educational solutions have to answer. ACT is interested and involved in developing metrics to measure the Global Programming success, but they are still under development.

Therefore, COEs (or other ETFs) have to define their own relevant performance indicators based on their position in the NATO Global Programming stakeholders' picture. For the institutions ensuring the function of Department Head (DH) - which is the case for several COEs - the success may be quantified as a positive evolution in time for:

- the number of ETFs adhering to the E\&T Community of Interest managed by $\mathrm{DH}$;

- the number of courses identified as solutions for NATO E\&T requirements (starting from the initial assessment in the Training Requirements Analysis (TRA) and following with Training Needs Analysis (TNA);

- the number of satisfied E\&T requirements out of those listed in the TRA, reflected in the importance, relevance, confidence given, and adequacy of the correspondent Performance Objectives;
- the initiatives supporting the enhancement of E\&T delivery and development of different projects;

- proposals of E\&T remedial solutions as a result of observations analyzed in the LL/BP process; etc.

\subsection{Key Performance Indicators for Doctrine Development and Standardization}

Standardization inquires about the development and implementation of concepts, doctrines and procedures in order to achieve interoperability in different fields of interest. The management of the NATO concepts, doctrines, standards or directives - usual references for the development of the courseware in the E\&T process - is widely covered by NATO COEs, either as custodians or contributing subject matter experts.

The standardization process has clearly defined outcomes, with a declared scope, and adjusted to the content and the target audience. From these aspects derive their importance and the quality requirements. As C. Akșit, former director of the NATO Standardization Agency, has outlined, the standardization management is a living system, which requires inputs, processes, outputs and feedback. [27] The feedback actually ensures the quality control, by providing a certain level of user/ customer satisfaction to the entire spectrum of the elements within the system (figure 4). 


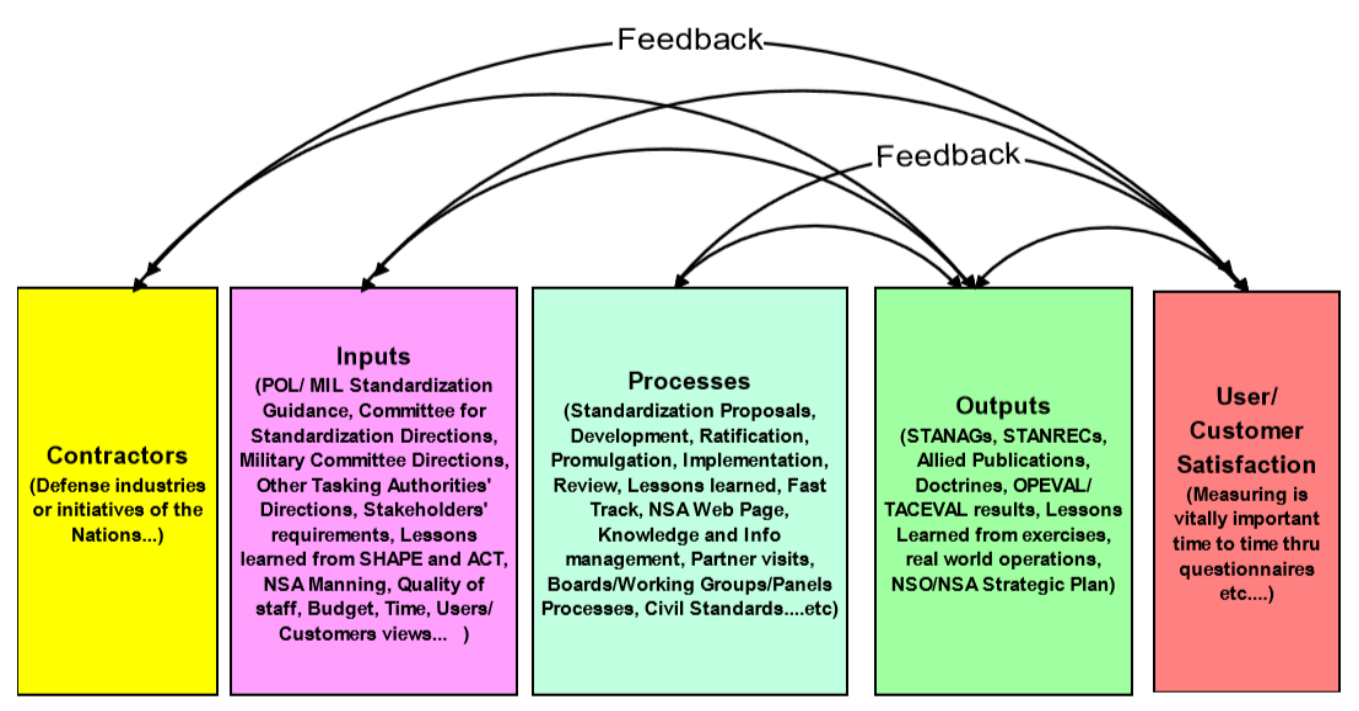

Figure 4: Quality Control in the NATO Standardization System [28]

Following the path of a COE - custodian for a discipline's standard(s) (doctrine and/or procedures), customers' satisfaction metrics are collected trough questionnaires and interviews applied in the educational/ training events and within the operational environment. Feedback is also collected by the means of the LL/BP process. Systematically addressed, all these aspects contribute to the recognition of the publication's status as "validated", as long as it matches an agreed quality matrix.

KPIs for a doctrine and standards development section may focus on:

- quantity indicators (applied to different units of time and based on relevance):

○ number of validated standards;

- number of publications issued/ revised;

- number of studies developed in support of standardization;

- number of other standards checked for harmonization in different working groups;

- quantification of the contribution to the development of other standards;

- number of definitions developed/ revised in the terminology management process; etc.

- quality indicators (derived from customers' satisfaction surveys): $\circ \%$ of content coverage for the knowledge necessary to perform the job's tasks;

○ clarity/ readability level;

o structure of a specific standard;

$\circ$ usefulness of pictures/ diagrams; and others.

NATO doctrines at operational level are regularly assessed in the exercises conducted by the Norway-based Joint Warfare Center (JWC) - the premier training establishment of NATO at the operational level - based on an established methodology and the validation programme issued by ACT. The custodian still may have a contribution by participating with subject matter experts in the evaluation/ validation teams. The key for this validation is - once again - the customer's satisfaction, thus utility of a doctrine for the purposed target audience.

However, things are more complex for a custodian in validating the specialty level standards, considering that the whole methodology (still customer-oriented) falls into his responsibility. In this case, the "success" can be assessed more in detail, covering multiple aspects of standardization effectiveness (and having as final goal the improvement). 


\subsection{Key Performance Indicators for Concept Development}

NATO Concept Development and Experimentation (CD\&E) encompasses a complex process consisting of developing new concepts/ solution-oriented transformational ideas (innovation) that address a capability shortfall or gap, a process reinforced by the controlled and directed activity designed to discover new information about a concept, test a hypothesis, or validate a solution (the experimentation). [29]

Measurement of performance in $\mathrm{CD} \& \mathrm{E}$ is given, above everything, by the successful implementation of the outcomes foreseen by the carried projects. However, this is not easy to quantify at a small scale represented by a particular COE. In spite of this, the analysis of the concept development stages ensure that the criteria for good experimentation are followed with the aim of establishing:

- Validity: It will do what we expect it to do;

- Feasibility: We can do what we want given the constraints;

- Applicability: It make sense given the situation;

- Robustness: It can withstand criticism;

- Credibility: Information gained contributes to the sum of our knowledge. [30]

The most accessible option to implement measurement indicators for a CD\&E structure/ activity in a COE is to consider the current practice from project management KPIs, related to:

- project completion estimates/ deadlines crossing;

- issues found by different categories of stakeholders/ customers;

- number of unresolved issues;

- project resource allocation/ utilization project sustainability;

- current development backlog;

- customer satisfaction, etc. [31]
4.4 Key Performance Indicators in Lessons Learned/ Best Practices Management

Lessons Learned/ Best Practice management also goes for project management - like KPIs, with focus on quantity of passively and actively collected observations, processed data, analysis figures and final outcomes (remedial proposals).

The utility of the LL/BP process in driving the transformation processes - initiating new concepts development or either contributing to doctrinal/ procedures updates - worth being quantified, being in line with the expected finality of the LL/BP management.

Beside this, the administration of the LL/BP Community of Interest brings to the attention figures reflecting customers' insight and interest in a data base, or stakeholders' contribution to the common threshold.

\section{Conclusions}

From an institutional perspective, the value of the system is given by the value of its composing entities and the added value of their synchronized and coordinated work. On the organizational chart, it starts with the management level (COE leadership), continues with the functional and support structures, and ends down at individual level.

Thus, establishing KPIs as control tool and metrics measuring the institutional success in NATO COEs is a complex activity that has to address multiple levels:

- strategic, linked to the COE's mission, the leadership vision and the adopted strategy;

- operational, where contribution of the functional areas to their objectives derived from the COE's strategic goal is quantitatively and qualitatively quantified; bottom-up figures can be equally addressed in order to emphasize particular aspects of higher relevance; 
- the resources/ support level, which ensures the unit's sustainability and supports the program of work (this last level was not addressed in this paper, as long as the organization and attributes of the encompassed structures follow widespread control and performance measurement models).

KPIs have to follow several rules for being effective, but the "so what?" question remains essential. Users must acknowledge the value of the KPIs' outcome and facilitate a thorough selection of relevant indicators. In this respect, each structure responsible for a functional area has to determine a set of critical questions, gathered into a questionnaire, and applied to different samples of target audience and in different environments connected to their work.

Keep asking is the second command in ensuring KPIs' effectiveness. Figures have to be captured permanently and assessed periodically, being further used as change/ transformation enablers/ vectors (part of the continuous improvement process). Therefore, a distinction between what is relevant for depicting an institutional diagnosis and what should be addressed as an operational control and correction instrument should be carefully made.
KPIs can also lead to perverse incentives and inadvertent effects as a result of working to pump specific metrics at the expense of the actual quality or value of the work. [32] In this respect, a permanent SWOT analysis of the KPIs and their relevance will allow the consolidation and maturity of the system.

Further on, choosing the right wedges for the dashboard view is not only imagination, but science. The first temptation is to visualize ascending arrows from left to right, but this is not an exclusive and sufficient option. The right choice is connected to the question of what a deciding person needs to see in order to understand from a snapshot the status of a cluster of processes and to support any decision affecting the course of the projects. The view can be customized to better serve this purpose.

We will finalize by re-stating the importance of KPIs in the institutional Quality Management System. Some NATO COEs already have a certain level of expertise in this domain; some are just in the way to develop their own KPIs system. Thus, we hope that this paper will provide a useful insight in the current practice and sufficient tips for building procedures and tools for measuring the NATO COEs' institutional success.

\section{References}

[1] Gregory Daddis, No Sure Victory: Measuring U.S. Army Effectiveness and Progress in the Vietnam War, 2011.

[2] CA Technologies, White Paper: Key Performance Indicators: Establishing the Metrics that Guide Success, in https://www.ca.com/content/dam/ca/us/files/white-paper/keyperformance-indicators.pdf, 2015.

[3] CA Technologies, White Paper: Key Performance Indicators: Establishing the Metrics that Guide Success, in https://www.ca.com/content/dam/ca/us/files/white-paper/keyperformance-indicators.pdf, 2015.

[4] Steven Few, Information Dashboard Design: The Effective Visual Communication of Data, O'Reilly, 2006.

[5] https://powerpivotpro.com/2015/05/datazen-beautiful-mobile-dashboards/

[6] http://www.conceptdraw.com/How-To-Guide/performance-indicators 
[7] Allied Command Transformation, COE Catalogue 2018, Version: 2018 V1, Graphics Print Jobs: HQ SACT Graphic \& Reproduction, p. 33, 2017.

[8] MCM 0236-2003, 04 December 2003.

[9] IMSM-0416-04, NATO Centres of Excellence Accreditation Criteria, 11 June 2004.

[10] Allied Command Transformation, COE Catalogue 2018, Version: 2018 V1, Graphics Print Jobs: HQ SACT Graphic \& Reproduction, p. 64, 2017.

[11] Eduard Simion and Alexandru, Kis, New features of the NATO Centres of Excellence in support of the North-Atlantic Alliance Transformation, Proceedings of the $22^{\text {nd }}$ International Conference "The Knowledge-Based Organization", pp. 125-131, Sibiu, Romania, 2016.

[12] HQ SACT formal letter, Quality Assurance Unconditional Accreditation for Human Intelligence Centre of Excellence, 15 October 2013.

[13] https://e-itep.act.nato.int/Guest/ETOCindex.aspx

[14] Allied Command Transformation, Institutional Accreditation - NATO Quality Assurance, http://www.act.nato.int/qa, 2018.

[15] DRESMARA, Academic Quality Assurance Policy, Edition 1, rev. 3, pp.54-55, in http://www.dresmara.ro/resources/quality.pdf, 2018.

[16] NATO MP COE, Quality Assurance Policy, p. 14, in http://mpcoe.nazwa.pl/images/QA/2016\%20NATO\%20MPCOE\%20QA\%20Policy.pdf, 2018.

[17] https://ciedcoe.org/index.php/department-head/quality-assurance-qa

[18] CIMIC COE, The CIMIC COE QA Policy, in https://www.cimic-coe.org/wpcontent/uploads/2014/07/20140710_UC_CCOE_QA_Policy_01_Main-document.pdf, 2018

[19] https://www.iso.org/standard/46486.html ISO 9001:2008

[20] MILMED COE, MILMED COE Policy, pp. 11-12, in http://www.coemed.org/images/stories/policy_documents/MILMED\%20COE\%20QA\% 20Policy.pdf, 2016.

[21] MILMED COE, MILMED COE Policy, pp. 18-19, in http://www.coemed.org/images/stories/policy documents/MILMED\%20COE\%20QA\% 20Policy.pdf, 2016.

[22] NATO Stability Policing COE, NATO S\&P COE Strategic Plan 2016-2018, edition 1, in http://www.nspcoe.org/docs/default-source/Public/document-library/nato-sp-coestrategic-plan-2016_2018.pdf?sfvrsn=2, 2016.

[23] Douglas H. Walker, Developing Metrics for the Global War on Terrorism, Joint Military Operations Department, Naval War College, Newport, in http://citeseerx.ist.psu.edu/viewdoc/download?doi=10.1.1.888.5371\&rep=rep1\&type $=\mathrm{p}$ df, 2005.

[24] Eduard Simion and Alexandru Kis, New features of the NATO Centres of Excellence in support of the North-Atlantic Alliance Transformation, Proceedings of the $22^{\text {nd }}$ International Conference "The Knowledge-Based Organization", pp. 125-131, figure 9, Sibiu, Romania, 2016. 
[25] NATO, NATO Bi-SC Education and Individual Training Directive 075-007, p. 70, in https://www.act.nato.int/images/stories/structure/jft/ptecs/etd-075-007.pdf, 2015.

[26] NATO, NATO Bi-SC Education and Individual Training Directive 075-007, pp. 65 - 70 $\&$ Annex S, in https://www.act.nato.int/images/stories/structure/jft/ptecs/etd-075007.pdf , 2015.

[27] Cihangir Akşit, Smart standardization: a historical and contemporary success at NATO, NATO Standardization Agency, p. 2, in https://www.nato.int/nato_static_fl2014/assets/pdf/pdf_2014_05/20140528_140528smart-standardization.pdf, 2014.

[28] Cihangir Akşit, Smart standardization: a historical and contemporary success at NATO, NATO Standardization Agency, p. 3, fig. 1, in https://www.nato.int/nato static fl2014/assets/pdf/pdf $2014 \quad 05 / 20140528 \quad 140528$ smart-standardization.pdf , 2014.

[29] Allied Command Transformation, Leaflet: Shaping Concept Development and Experimentation for the Future. Introduction: NATO Concept Development \& Experimentation Defined, in http://www.act.nato.int/images/stories/events/2014/cde/cde2014ra_1a.pdf, 2014.

[30] Han de Nijs, Concept Development and Experimentation Policy and Process: How Analysis Provides Rigour, HQ Supreme Allied Command Transformation, Capability Engineering Division, Operational Analysis Branch, Norfolk, Virginia, USA, in RTOMP-SAS-081, p. 21-10, www.dtic.mil/get-tr-doc/pdf?AD=ADA584337, 2010.

[31] https://www.scoro.com/wp-content/uploads/2017/03/KPI-Examples-Download.pdf

[32] Robert D. Austin, Measuring and Managing Performance in Organizations Paperback, Publisher: John Wiley \& Sons, 1996. 